\title{
CIRCULATORY ADJUSTMENT IN ANEMIA
}

BY DICKINSON W. RICHARDS, JR., AND MARJORIE L. STRAUSS

(From the Department of Medicine, Columbia University, College of Physicians and Surgeons, and the Presbyterian Hospital, New York City)

(Received for publication October 6, 1927)

Previous studies of the circulation rate in man in various types and degrees of anemia $(1,2,3)$ have concerned themselves chiefly with comparisons of circulation rates of groups of anemic individuals with the rates of normal individuals.

Inasmuch as the normal rate varies greatly from one individual to another, it occurred to us that it might be of interest to study the cardiac output as well as other functions of the circulation of a given subject while in the anemic state and also at intervals during his recovery. It would thus be possible to show in that individual the adjustment to the condition of anemia; and a group of such studies might give a clearer picture of the adaptive process than could be obtained from purely statistical data on circulation rates and related functions.

The present investigation is a study of the cardiac output in eight anemic subjects both during the stage of anemia and at intervals in the period of recovery. The initial oxygen capacities of the blood varied from 5.4 to 14.4 volumes per cent. Two were suffering from primary anemia, four from secondary anemia following hemorrhage from gastric or duodenal ulcer, one from secondary anemia with carcinoma of the stomach, and one had a secondary anemia associated with purpuric manifestations. When the experiments were made, the subjects were in all instances apparently well compensated to their anemia; while at rest in bed, temperature, respiratory rate and pulse rate were within normal limits except that on two occasions the pulse was as high as 90. All experiments were done in the morning, under basal conditions: that is, after at least 12 hours without food, and half an hour of complete rest in bed. 
The data which were measured in each experiment were: (1) alveolar and oxygenated "mixed venous" $\mathrm{CO}_{2}$ tensions, (2) minute volume, and $\mathrm{O}_{2}$ and $\mathrm{CO}_{2}$ percentages, of expired air, (3) $\mathrm{CO}_{2}$ dissociation curve of venous blood, (4) oxygen capacity of venous blood.

From these data were calculated: (5) cardiac output per minute (Field-Bock method), (6) arterial and venous serum $\mathrm{pH},(7)$ oxygen consumed per $100 \mathrm{cc}$. of blood, (8) oxygen consumed per cent of capacity, (9) basal metabolic rate and, (10) respiratory quotient.

\section{METHODS}

For the measurement of cardiac output per minute, our method was essentially that of Field, Bock, Gildea and Lathrop (5), with a few modifications in apparatu s

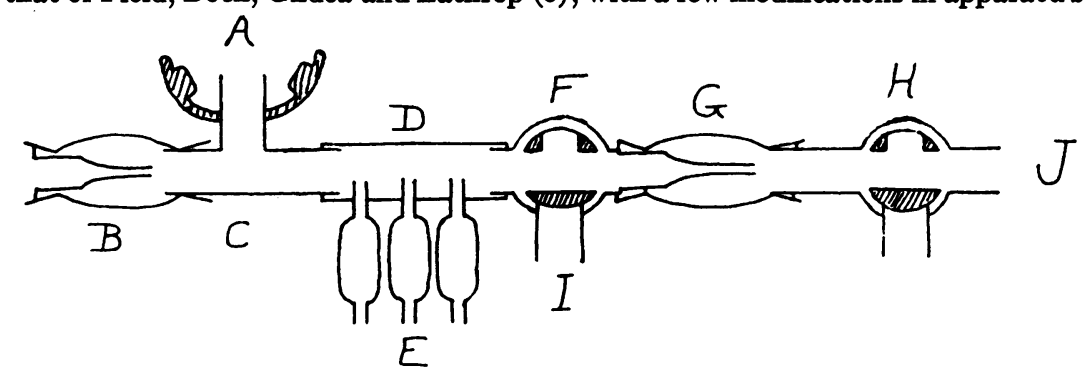

Fig. 1. Diagram of Modified Field-Bock Apparatus for Measuring Cardiac Output, for Portable Use

$A$, mouthpiece; $B$, intake flutter valve; $C$, brass " $\mathrm{T}$ " tube; $D$, rubber tubing; $E$, gas sampler vessels; $F$ and $H, 3$-way valves; $G$, flutter valve; $I$, opening for attachment of rebreathing bag; $J$, opening for attachment of Douglas bag.

which we made chiefly for purposes of compactness, in order that the apparatus might be easily portable on the wards.

The apparatus is illustrated diagrammatically in figure 1. To the base of a small " $T$ " tube of $\frac{3}{4}$-inch brass tubing is fitted the rubber mouthpiece. To one arm of the " $\mathrm{T}$ " tube is attached a flutter valve, the valve being brought as close as possible to the mouthpiece tube, in order to diminish the dead space. To the opposite arm of the " $T$ " tube is attached a piece of stiff rubber tubing, perforated by three small holes for the insertion of the ends of gas sampler vessels. Beyond the rubber tubing are attached, successively, a three-way valve, a second flutter valve, and another three-way valve.

${ }^{1} \mathrm{By}$ this phrase is meant the $\mathrm{CO}_{2}$ tension of mixed venous blood, estimated from modified alveolar air presumably in equilibrium with mixed venous blood in the pulmonary capillaries. 
The gas samplers were glass vessels of 25 to $30 \mathrm{cc}$. capacity, with a stopcock at each end. They were arranged in sets or batteries of three, each set fastened to a wooden back for support and attached by glass tubing and a length of about 75 $\mathrm{cm}$. of rubber pressure tubing to a single thistle tube of mercury. With this,

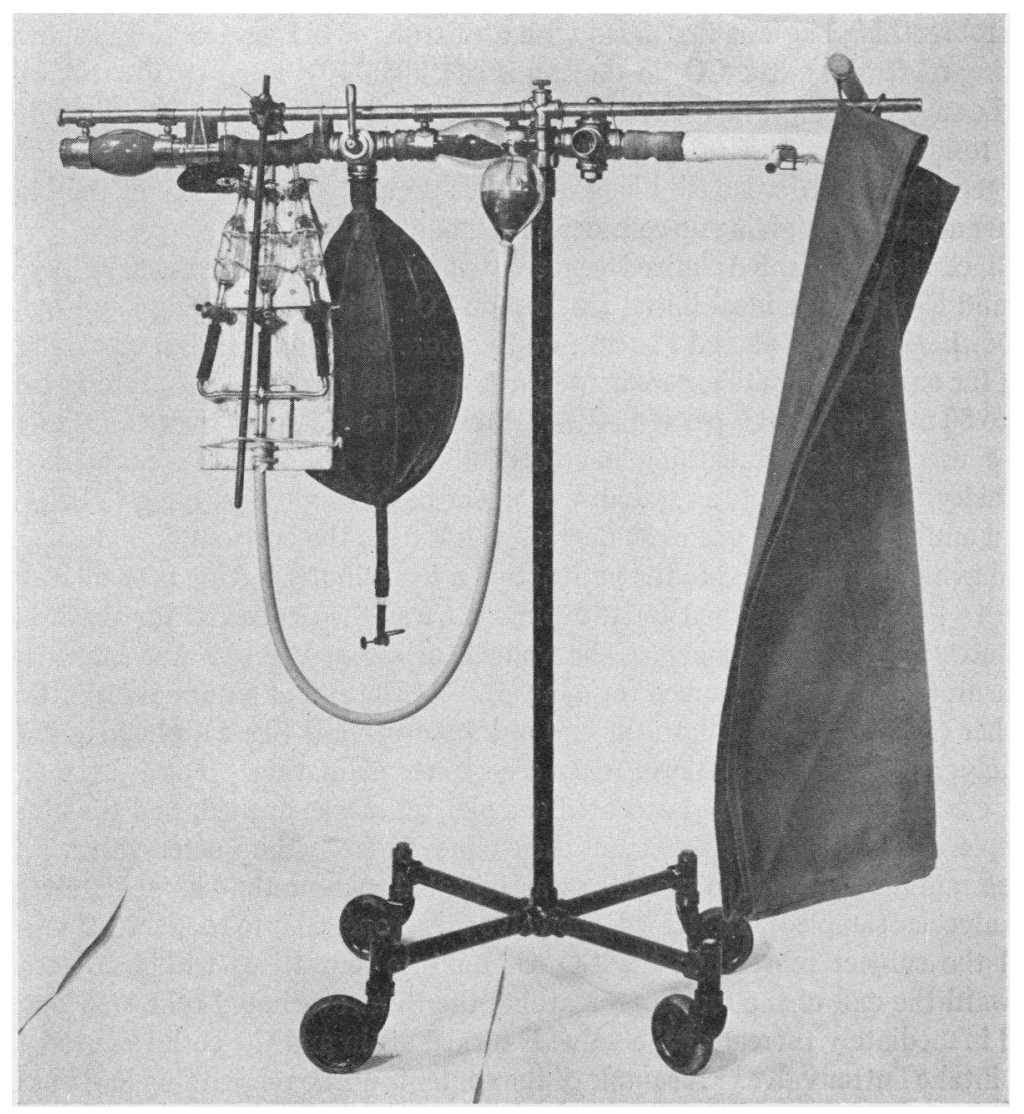

Fig. 2. Modified Field-Bock Apparatus for Measuring Cardiac Output, FOR PORTABLE USE

In actual use, the gas samplers are tipped up horizontally, to lift them above the bed or subject's body.

all three samplers could be evacuated by a single lowering of the mercury. As far as ease and rapidity of collection of samples are concerned, the advantage of having a Torricellian vacuum in the sampling tubes is obvious.

To the side opening of the first three-way valve, the re-breathing bag containing 
the $\mathrm{CO}_{2}-\mathrm{O}_{2}$ mixture was attached; and to one opening of the three-way valve at the end, a Douglas bag of 100 liters capacity.

The whole apparatus was suspended on a small stand provided with rollers (fig. 2).

The technique which we used for estimating the cardiac output was as follows: the rebreathing bag was first filled with a mixture of $\mathrm{CO}_{2}$ and $\mathrm{O}_{2}$. Inasmuch as, during rebreathing, the $\mathrm{CO}_{2}$ in the bag is considerably diluted by the residual air in the subject's lungs, we used an initial tension in the bag which when diluted with the residual air would bring the resultant mixture to about the tension of the oxygenated "mixed venous" blood, and thus prevent the necessity of the blood's either absorbing or giving up considerable amounts of $\mathrm{CO}_{2}$.

Since the oxygenated "mixed venous" tensions of $\mathrm{CO}_{2}$ varied usually between 42 and $50 \mathrm{~mm}$., the ideal initial tension for $\mathrm{CO}_{2}$ in the rebreathing bag would be somewhere between 45 and $55 \mathrm{~mm}$.; we therefore used as the initial tension in the bag for our experiments approximately the mean of these tensions, that is to say, 48 to $50 \mathrm{~mm}$. or about 7 per cent $\mathrm{CO}_{2}$. From 2.5 to 4 liters of the $\mathrm{CO}_{2}-\mathrm{O}_{2}$ mixture were used in the rebreathing bag, depending on the patient's probable vital capacity. The subject, as stated, was under basal conditions, lying in bed, with head and body at an angle of 30 degrees or less from the horizontal. The apparatus having been adjusted to the patient and a few minutes having been allowed for him to become accustomed to it, expired air was then collected for six or seven minutes in the Douglas bag. The volume of air in the bag was immediately measured, and a sample taken for analysis. At the end of a normal expiration, a rubber cork was inserted into the end of intake valve B (fig. 1), plugging it completely, and the subject told to make a complete expiration. Toward the end of this expiration, one of the evacuated sampler tubes was opened, and the alveolar sample sucked in. The cork was then removed from the flutter valve. After three minutes, the same procedure was repeated, except that immediately after the alveolar sample was obtained, the valve $\mathrm{F}$ was opened into the rebreathing bag, and the subject rebreathed the $\mathrm{CO}_{2}-\mathrm{O}_{2}$ mixture four times within 20 seconds. Toward the end of the fourth rebreathing the third evacuated tube was opened, and immediately thereafter the valve $F$ turned again and the cork removed from the intake flutter valve. A sample of the contents of the rebreathing bag was then taken.

After a few minutes' rest, this entire procedure was repeated. Thus at the end of the experiment, there were obtained for analysis four alveolar air specimens, four "mixed venous" specimens, and two six- or seven-minute volumes of expired air.

This technique involving as it did several variations from that described by Field, Bock, Gildea and Lathrop, it was necessary to check our method in various ways. Air samples obtained by evacuated tubes and by ordinary sampling tubes were found to be the same. By the use of evacuated tubes, we investigated the effect of rebreathing from the $\mathrm{CO}_{2}-\mathrm{O}_{2}$ bag by taking samples after each rebreathing; and we found, as others have done, that the samples after the third and fourth 
rebreathings were practically the same, and were the same as the contents of the bag after rebreathing. We next compared the alveolar airs obtained by our method with Haldane-Priestley samples, in order to ascertain whether the air enclosed in the dead space in flutter valve B would be partly sucked into the sampling tube and dilute the sample. This was found to be the case, these alveolar airs being an average of $0.4 \mathrm{~mm}$. lower in $\mathrm{CO}_{2}$ tension than the HaldanePriestley samples. By filling in as much of the dead space in flutter valve $B$ as possible with plasticine clay, this discrepancy was reduced to an average of $0.25 \mathrm{~mm}$.

In order to test the apparatus further, alveolar airs were compared directly with arterial blood. A series of alveolar air samples was taken, usually five, using the apparatus as described above, and during this procedure arterial blood drawn. To avoid as far as possible changes in pulse rate and respiration during the drawing of blood, the method of Goldschmidt and Light (6) was used, one hand being immersed in hot water for 10 minutes, and blood then taken from a hand vein into a vessel containing oil and enough dried neutralized potassium oxalate to make a final concentration of about 0.2 per cent. Blood so obtained was in every case between 94.5 and 96 per cent saturated with oxygen and so presumably practically identical with arterial blood, as Goldschmidt and Light also found. The arterial $\mathrm{CO}_{2}$ content was measured, a $\mathrm{CO}_{2}$ dissociation curve constructed with oxygenated blood, and the average alveolar air tension compared with the tension on the 95 per cent oxygenated $\mathrm{CO}_{2}$ curve, at the point determined by the arterial $\mathrm{CO}_{2}$ content. In a series of six such measurements, the alveolar air $\mathrm{CO}_{2}$ tensions varied from the arterial as follows: $-1.4 \mathrm{~mm} .,+0.3 \mathrm{~mm} .,-2.2 \mathrm{~mm} .,-0.3 \mathrm{~mm} .,-1.5$ $\mathrm{mm}$., and $0 \mathrm{~mm}$., an average of $-0.85 \mathrm{~mm}$. In a similar series of 15 measurements by Field, Bock, Gildea and Lathrop, an average of $-0.48 \mathrm{~mm}$. was obtained. It is thus likely that the apparatus which we used gave alveolar air specimens that were about $0.3 \mathrm{~mm}$. lower than those obtained by the original Field-Bock method. ${ }^{2}$ We have, however, retained the $1.0 \mathrm{~mm}$. correction factor used by these authors, for the reason that the discrepancy is small, and the further reason that the difference in level between the arterial and the completely oxygenated blood $\mathrm{CO}_{2}$ curve, which accounted for $0.5 \mathrm{~mm}$. of this correction factor, is probably less in anemic bloods, since 5 per cent unsaturation in anemic blood would cause less displacement of the $\mathrm{CO}_{2}$ curve than 5 per cent unsaturation in normal blood.

We made several attempts to obtain arterial blood samples from the subjects during or just after the estimations of cardiac output but in most instances were unable to do this without definite changes in the subject's pulse rate and respiration. Two such attempts, in which there was relatively little change in these factors (first experiments on J. K. and on J. H.) gave arterial blood tensions that were $-2.8 \mathrm{~mm}$. and $+1.8 \mathrm{~mm}$. respectively from the mean alveolar air tensions.

\footnotetext{
${ }^{2} \mathrm{~A}$ modification of the apparatus has been made wherein a small slide-valve is inserted between flutter valve $B$ and the mouthpiece, thus enabling more exact Haldane-Priestley alveolar air samples to be taken.
} 
Since the Field-Bock method gives arterial and venous $\mathrm{CO}_{2}$ tensions, which have to be transferred into terms of $\mathrm{CO}_{2}$ contents by the use of the slope of the $\mathrm{CO}_{2}$ curve, it was necessary in these experiments to determine the $\mathrm{CO}_{2}$ curve on each occasion, because the slope of the curve varies chiefly with the hemoglobin content of the blood. In all our later experiments, the curve was constructed from 2 points, usually about 25 and $50 \mathrm{~mm}$. tensions, using logarithmic paper and Peters' straight line logarithmic relation. In some of the earlier experiments, three or more points were determined. In four instances, $\mathrm{CO}_{2}$ curves were not constructed, and the slopes only estimated (table 1).

Gas analyses were made with the Haldane apparatus; the blood gas analyses by the Van Slyke-Neill apparatus. The technique of equilibrating and handling blood samples was that of Austin, Cullen, Hastings, McLean, Peters and Van Slyke (19) with a few slight modifications.

With the $\mathrm{CO}_{2}$ curves which we were constructing, it soon became evident that the slope was in most cases nearly a direct function of hemoglobin concentration. This relationship was established by Peters, Bulger and Eisenman (7) a few years ago, in a large number of experiments. Using $\mathrm{CO}_{2}$ contents at 30 and $60 \mathrm{~mm}$. tensions, these authors found that the differences between the contents at these two tensions, for varying oxygen capacities, could be represented approximately by the formula:

$$
\Delta\left[\mathrm{CO}_{2}\right]_{60-30}=0.334 h+6.3
$$

where $h=$ oxygen capacity in volumes per cent. This difference in $\mathrm{CO}_{2}$ content at constant tension difference is a measure of the slope of the curve. If, therefore, one uses this relation in the form of a ratio, $\frac{0.334 h+6.3}{0.334(20)+6.3}$ and multiplies this ratio by the standard slope values for normal blood (oxygen capacity of 20 volumes per cent) as given by Field, Bock, Gildea and Lathrop, the product will be a fairly close approximation to the actual slope of the $\mathrm{CO}_{2}$ curve for blood of oxygen capacity $h$. We have calculated these values for each experiment (table 1). The agreement with the actual $\mathrm{CO}_{2}$ curve slopes is good, the difference being less than 10 per cent in every case but one. Comparing our findings in this respect with the fifty-one experiments of Peters, Bulger and Eisenman, on which the formula is based, it was found that our results showed less marked deviations than did theirs. The scattering of the points in their experiments, however, as they themselves pointed out, occurred to a much greater degree with bloods of high oxygen capacity than with low. If the thirteen experiments which these authors made using bloods of less than 14 volumes per cent oxygen capacity are considered, it is found that all the points fall close to the line determined by their formula (the deviation being less than 10 per cent) except one. In future investigations of anemic bloods, the use of the adaption of this formula with the Field-Bock value for normal slope of the $\mathrm{CO}_{2}$ curve, may be expected, therefore, to give results at least as accurate as would the use of these "normal" values for different bloods of normal or nearly normal oxygen capacities. 
It has been recognized for some time that the accuracy of the gasometric method of calculating cardiac output depends on the accuracy of estimating its most variable element, namely, the alveolar air measuremetits vilai istudying untrained subjects, we have in this respect, encountered some sdifficulty at times. Frequently one, and occasionally more than one, of the four alveolar air measurements was quite far from the others, so for calculating both alveolar air and "mixed venous" tensions we adopted the method of the mean, discarding the highest and lowest figures and taking the average of the middle two. In order to give some idea of the error of the method we have in table 1 included both of the two mean alveolar air determinations of each experiment.

For a reason which will be discussed presently, it was of interest to us to calculate the $\mathrm{pH}$ of arterial and venous serum for each experiment. The arterial point was taken as the point on the oxygenated $\mathrm{CO}_{2}$ curve determined by the level of the mean alveolar $\mathrm{CO}_{2}$ tension; the $\mathrm{pH}$ being calculated by the HendersonHasselbalch formula, using the method worked out by Peters, Bulger, and Eisenman (8). The actual arterial point is slightly above and to the right of the point from which our calculations have been made, but the difference in $\mathrm{pH}$ of the two points is negligible. The actual "mixed venous" point on the diagram of the $\mathrm{CO}_{2}$ dissociation curve lies on the line of the content of oxygenated "mixed venous" $\mathrm{CO}_{2}$, but to the left of the oxygenated $\mathrm{CO}_{2}$ curve. This distance is such that the point lies above that curve by an amount determined by the oxygen unsaturation of the venous blood. Since we have measured the utilization of $\mathrm{O}_{2}$ per $100 \mathrm{cc}$. of blood, ${ }^{3}$ and since we know from the work of Bock, Field, and Adair (9) the number of volumes per cent $\mathrm{CO}_{2}$ taken up in complete reduction of normal blood at constant $\mathrm{CO}_{2}$ tension (about 6.2 volumes per cent) it is easy to calculate approximately the loss of $\mathrm{CO}_{2}$ tension of the actual mixed venous blood due to oxygen unsaturation. This formula is:

$$
{ }_{p}\left(\mathrm{CO}_{2}\right)_{a}={ }_{p}\left(\mathrm{CO}_{2}\right)_{0}-\left(\frac{\Delta \mathrm{O}_{2} \mathrm{cc} .}{20} \times 6.2\right)\left(\frac{1}{s}\right)-0.5
$$

where ${ }_{p}\left(\mathrm{CO}_{2}\right)_{a}=$ actual mixed venous $\mathrm{CO}_{2}$ tension, ${ }_{p}\left(\mathrm{CO}_{2}\right)_{0}=\mathrm{CO}_{2}$ tension of oxygenated mixed venous blood, $s=$ slope of the $\mathrm{CO}_{2}$ curve and $\Delta \mathrm{O}_{2} \mathrm{cc}$. $=$ tissue utilization of oxygen per $100 \mathrm{cc}$. of blood. The figure 6.2 has been explained, and 20 is the total volumes per cent oxygen unsaturation of normal reduced blood. The last figure, 0.5 , is the approximate difference in tension between completely oxygenated and arterial ( 95 per cent oxygenated) blood.

Metabolic rate calculations have been made using the DuBois height-weightsurface area relation, and the value of 4.8 calories per liter of $\mathrm{O}_{2}$ per hour, irrespective of the respiratory quotient.

${ }^{3}$ This is obtained from the difference in $\mathrm{CO}_{2}$ content of arterial and venous blood by dividing by the respiratory quotient. 


\section{. vesg adt ju vesius RESULTS}

riteg io rosiur

On the eight $\mathrm{t}_{2}$ individisal subjects, twenty-two observations in all were made (Tablesiliband charts $\mathrm{A}$ to $\mathrm{F}$ of figure 3 ). The general results of the investigation are readily seen from these charts: (a) there is a definite though not entirely constant tendency for cardiac output to increase with decreasing hemoglobin concentration; (b) a practically constant increase of percentage utilization of oxygen by the tissues $\left(\Delta \mathrm{O}_{2}\right.$ per cent $)$ with increasing anemia, especially noticeable between 10 and 6 volumes per cent oxygen capacity; (c) a tendency to decrease of tissue utilization of oxygen per $100 \mathrm{cc}$. of blood $\left(\Delta \mathrm{O}_{2} \mathrm{cc}\right.$.), with decreasing oxygen capacity, (d) a relative increase in metabolic rate when the anemia is pronounced; (e) a tendency toward lowered respiratory quotient, which frequently rises as the oxygen capacity increases; (f) increased $\Delta \mathrm{pH}$ in severe anemia.

To summarize, as far as the data here presented are concerned, the general statement may be made that in the state of anemia, the burden, as it were, that is laid upon the rest of the circulatory apparatus as a result of diminished oxygen capacity, tends to be distributed, a part being taken by an increase in the cardiac output per minute and a part by increased percentage utilization of oxygen by the tissues. There are individual variations, the increased utilization at times taking almost all the burden. This appears particularly in the first experiments on F. L. and S. D. two primary anemias of long standing. Subject F. L. at this time was slightly edematous and subject S. D. markedly so; the latter's whole circulatory adjustment during her extreme anemia was in fact quite different from any of the others, and suggests beginning heart failure. The final experiment on this subject, however, shows an even more striking deviation from the rest of the group. There is reason to believe that in part at least this was due to faulty technique. The $\mathrm{CO}_{2}-\mathrm{O}_{2}$ mixture in the bag before rebreathing, was lower in $\mathrm{CO}_{2}$ tension than the subject's own oxygenated "mixed venous" tension. Evidence that equilibrium was not reached during rebreathing is given by the fact that the tensions of the samples taken at the end of the fourth rebreathing were 0.9 and $0.7 \mathrm{~mm}$. higher than the samples taken from the bag afterward. If equilibrium was not reached the $\mathrm{CO}_{2}$ tension difference between 

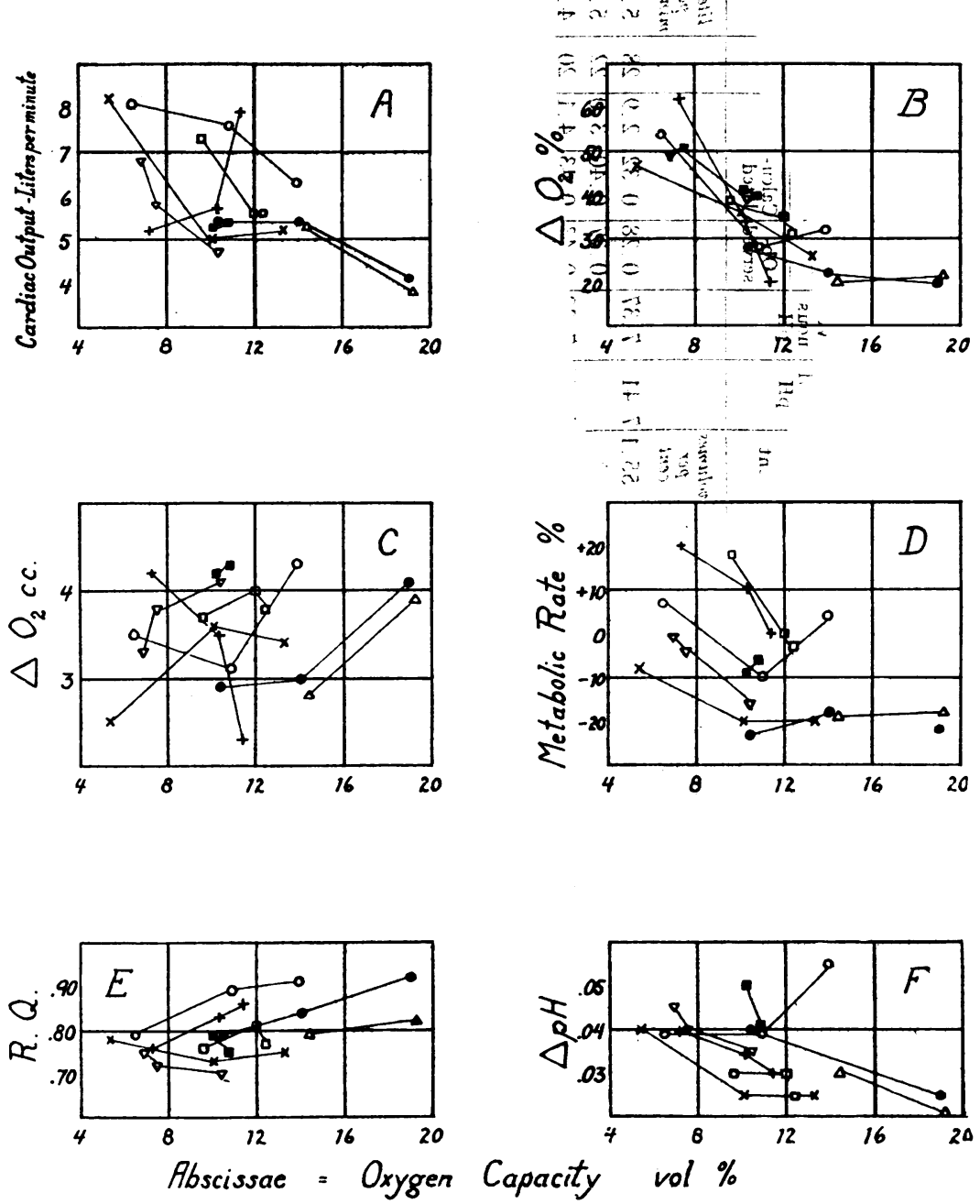

Fig. 3. Changes in Circulatory Functions in Anemia

Abscissae in each chart represent oxygen capacities in volumes per cent. $\Delta \mathrm{O}_{2}$ cc. $=$ oxygen utilized by the tissues, in cubic centimeters per $100 \mathrm{cc}$. of blood. $\Delta \mathrm{O}_{2}$ per cent $=$ oxygen utilized by the tissues in per cent of capacity (coefficient of tissue utilization). $\Delta \mathrm{pH}=$ difference between arterial and venous serum $\mathrm{pH}$.

Symbols indicate individual subjects: $\bullet=$ F. L. $\mathrm{O}=\mathrm{J}$. K. $\Delta=\mathrm{M} . \mathrm{H}$. $\square=$ J.H. $\square=$ W. S. $\nabla=$ N. B. $\quad+=$ S. D. $\times=$ J. J. 


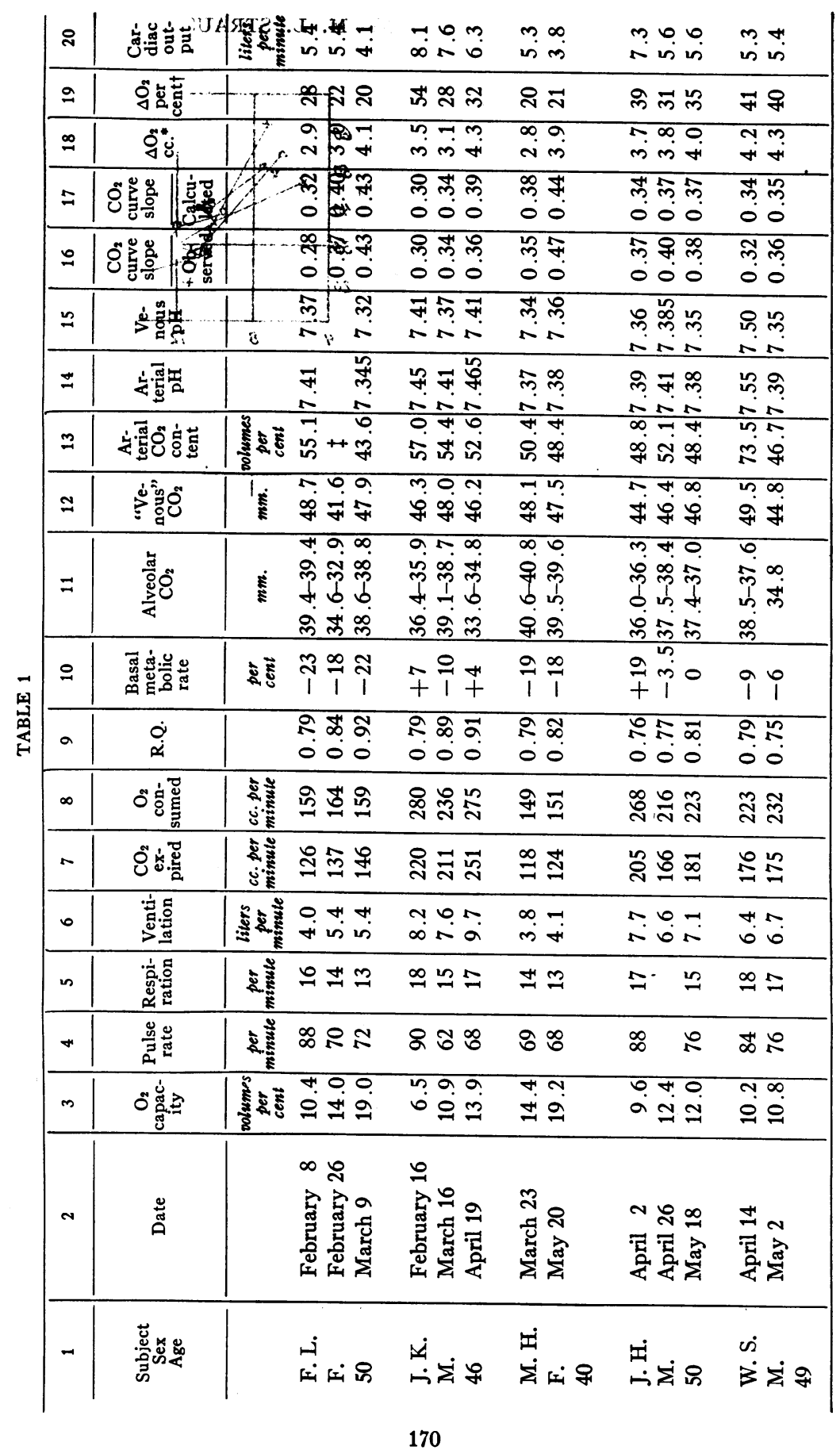




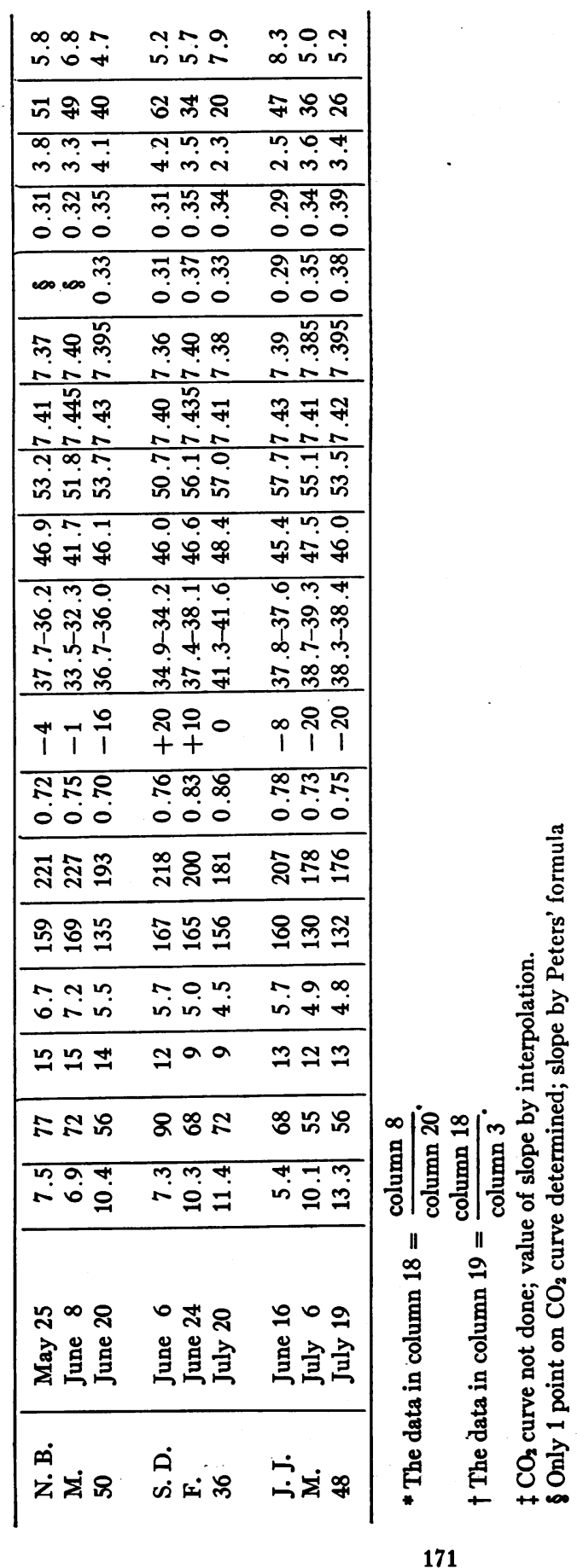


alveolar and "mixed venous" samples was too small and the cardiac output figure therefore too high. As there was no other evidence of error than this, however, the experiment was included with the others.

\section{DISCUSSION}

Of our general findings, (a), (b), (c) and (d) are entirely confirmatory of Liljestrand and Stenström's recent work on anemic subjects (3), using the Krogh-Lindhard nitrous oxide method, and are also consistent with Blalock and Harrison's (10) findings in dogs following repeated small hemorrhages.

Dautrebande (4) has recently reported a series of measurements of cardiac output, using Meakins and Davies' method, on a group of four subjects with anemia, at various stages of their disease. His findings were essentially these: at 20 per cent hemoglobin, two determinations, with cardiac outputs about 14 liters per minute; at 26 per cent hemoglobin one measurement, cardiac output 10.5 liters per minute; at 30 per cent hemoglobin, two measurements about 8 liters per minute; above 40 per cent hemoglobin, the cardiac outputs drop rapidly from 5 or 6 liters per minute to normal values, between 4 and 5 liters per minute. He followed one subject for several months, and found practically the same output on all occasions as long as the hemoglobin was above 50 per cent. Our data tend to show a continued fall in cardiac output with increasing oxygen capacity; they do not show, moreover, so sharp a rise in cardiac output between 40 and 25 per cent hemoglobin as do those of Dautrebande. Some of the discrepancy is probably due to the fact that the measurements made by Dautrebande were performed only 3 hours after the subjects' last meal, rather than under strictly basal conditions, and at these low levels of oxygen capacity a small increase in oxygen consumption would be expected to cause a considerable change in cardiac output.

Basal metabolic rates in anemia have been variously reported (DuBois 11), some investigators have found normal values, others an increase. Meyer and DuBois (12) in a very carefully conducted series of experiments on five cases of pernicious anemia, found the metabolic rate slightly raised in the mild cases, and distinctly raised in the severe cases. The only experiments which we have found in 
the literature, in which individual subjects were studied during recovery from anemia, were those of Tompkins, Brittingham and Drinker (13), who found regularly a decrease in metabolic rate following transfusions.

A lowered respiratory quotient has not, so far as we are aware, been noted by other investigators. The five cases reported by Meyer and DuBois had normal R.Q.s, except one, which was slightly low. Examination of the data in eighteen untreated cases of anemia as reported by Tompkins, Brittingham, and Drinker, however, shows that the respiratory quotients were all below 0.81 , with an average of 0.75 . Moreover, eight cases treated by transfusions, all showed a definite rise in respiratory quotient. These findings are in agreement

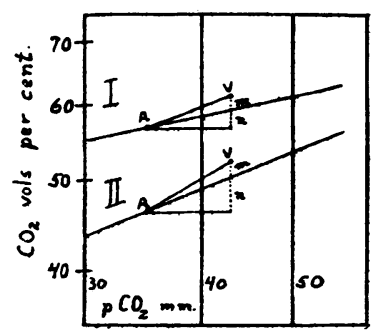

Fig. 4. $\mathrm{CO}_{2}$ Dissociation Curves Plotted Logarithatcally

$I$, anemic curve (subject J. J.). II, normal curve (subject M. H. after recovery). $m$, increase of $\mathrm{CO}_{2}$ content, oxygen unsaturation effect. $n$, increase of $\mathrm{CO}_{2}$ contents, buffer effect.

with our data; it is perhaps of interest to note that all the cases in our series that showed significant rise in respiratory quotient during recovery were on a "liver diet."

In view of the general tendency mentioned above, to "distribute the load," it becomes of interest to inquire further, if possible, into the mechanism of the distribution. In this respect the change in shape of the $\mathrm{CO}_{2}$ dissociation curve has certain consequences that may be pointed out. The flattening of the oxygenated and reduced curves, which occurs in anemic bloods, is presumably due to loss of cell proteins (chiefly hemoglobin), in their capacity as buffers. In the change from the arterial to the venous point, it can readily be seen from Figure 4 that if the $\mathrm{CO}_{2}$ tension differences remain the same, and 
$\Delta \mathrm{O}_{2}$ cc. is the same for the two bloods, $\Delta\left[\mathrm{CO}_{2}\right]$ will be considerably less in the anemic blood due to a decrease in the "cell-buffer" increment of $n$. In other words, the respiratory quotient will be diminished. To maintain a more nearly constant R.Q., at least three adjustments are possible; (a) a decrease in $\Delta \mathrm{O}_{2}$ cc., (b) an increase in the arterio-venous $\mathrm{CO}_{2}$ tension difference, or (c) displacement of both arterial and "mixed venous" $\mathrm{CO}_{2}$ tension lines to the left, where the $\mathrm{CO}_{2}$ curve is steeper. The decrease in $\Delta \mathrm{O}_{2}$ cc. would, of course, involve an increased blood flow, supposing the oxygen consumption to remain unchanged.

There is a further consequence of the altered form of the $\mathrm{CO}_{2}$ dissociation curve. Since the serum $\mathrm{pH}$ values on the dissociation curve diagram may be represented (following Y. Henderson) by straight lines radiating from the point of origin, it is obvious that a flattening of the $\mathrm{CO}_{2}$ curve will involve increase in the $\mathrm{pH}$ difference between arterial and venous blood (increased $\Delta \mathrm{pH}$ ). This increase will tend to be accentuated if the arterio-venous $\mathrm{CO}_{2}$ tension difference is increased, but diminished in proportion to the height of the curve above the base line. These considerations were pointed out several years ago by Barr and Peters (14). The net result is a distinct increase in the $\Delta \mathrm{pH}$ in anemia. This was noted in Barr and Peters' work, and appears in our data. Increased $\Delta \mathrm{pH}$ will, furthermore, increase the oxygen that can be taken up by the tissues at a given oxygen tension difference between arterial and venous blood, due to the lowering of the oxygen dissociation curves with increasing acidity. It is doubtful, however, if this effect on the percentage utilization of oxygen by the tissues will be a significant one, for two reasons; (1) reference to oxygen dissociation curves will show that such changes in $\Delta \mathrm{pH}$ as occur in anemia (table 1) are sufficient to increase the utilization at given $\mathrm{O}_{2}$ tension differences by only 3 or 4 per cent of the oxygen capacity at the most; (2) the actual effect is probably even less than this, since, according to the work of Barr and Peters, and others, the change in $\mathrm{pH}$ in anemia is usually due to a more alkaline arterial $\mathrm{pH}$ rather than a more acid venous $\mathrm{pH}$. As the $\mathrm{O}_{2}$ dissociation curves for different $\mathrm{pH}$ values are quite close to one another in the region of arterial saturations, small changes in acidity would 
produce correspondingly small changes in oxygen saturation, at constant oxygen tension.

When the percentage tissue utilization of oxygen is appreciably increased, therefore, there will be associated a diminished mean capillary oxygen tension, and presumably a diminished tissue oxygen tension. Decreased oxygen tension, as Krogh (15) has shown, produces both capillary and arterial dilatation. Liljestrand and Stenström (3) have called attention to the fact that increased percentage tissue utilization is consistent with increased capillary surface. Total cardiac output on the other hand, would be expected to increase, since this is the first effect of vasomotor (especially arterial) dilatation (Tigerstedt (16)). There is thus the possibility of a balanced relationship between cardiac output on the one hand, and mean capillary or tissue oxygen tension, or, what in this case amounts to the same thing, percentage tissue utilization, on the other. This proposition was suggested in part by Blalock and Harrison (10).

Blood pressure measurements unfortunately were not made in our series. Liljestrand and Stenström (3) found the mean arterial blood pressures to average 4 to $11 \mathrm{~mm}$. less in anemic subjects than in normal subjects. This is a small difference but is consistent with increased cardiac output and arterial dilatation, since according to Poisseuille's law an inverse relation between pressure and flow may exist providing there is simultaneously a small change in diameter of the channels of flow.

Between rates of 60 and 90 , increased pulse rate would be expected to produce increased cardiac output (17), other things being the same, and venous inflow to the heart being adequate. But if increased pulse rate were the dominant factor here - the peripheral blood vessels remaining unchanged-, one would expect an increased mean blood pressure.

Other factors concerned in estimating the magnitude of cardiac output in anemia are viscosity, and total blood volume. Viscosity is, of course, decreased, tending to increase cardiac output and decrease blood pressure; total blood volume is usually diminished (18) which will tend to decrease cardiac output.

It is clear from the data which we have charted, that the circulatory adjustments which actually take place in anemia are those which 
have suggested themselves in the preceding discussion; (1) lowered respiratory quotient, either absolute, or relative to subsequent values, (2) increased $\Delta \mathrm{pH}$, tending to diminish as the oxygen capacity increases, (3) decreased $\Delta \mathrm{O}_{2}$ cc. and increased $\Delta \mathrm{O}_{2}$ per cent, and (4) increased cardiac output. In this series, there was no consistent change in the arterio-venous $\mathrm{CO}_{2}$ tension difference in anemic as compared with normal blood.

That the above changes may be influenced by numerous factors other than those we have discussed, is obvious. One would not expect, for example, that so complex a function as the respiratory quotient would be largely determined by the form of the $\mathrm{CO}_{2}$ dissociation curve.

In extreme anemia, $\Delta \mathrm{O}_{2}$ per cent apparently approaches an upper limit. With this function no longer increasing, any further fall in oxygen capacity must result in a sharp decrease in $\Delta \mathrm{O}_{2}$ cc., and a corresponding rise in blood flow. These changes begin to be apparent in the first experiment on J. J. They are brought out still more clearly by Dautrebande's measurements (4), already referred to in subjects with only 20 per cent hemoglobin.

Our data, so far as we can see, do not throw any light on the fact of increased metabolic rate in severe anemia. Other investigators have ascribed this increase either to increased cardiac work attendant on increased output, or else to increased bone marrow activity. Tompkins, Brittingham, and Drinker (13) were inclined to the latter explanation since in their studies, the rate diminished following transfusions. Of the five cases in our series in which the metabolic rate decreased with improvement of anemia, four received transfusions during the interval, while in one case (S. D.) the rate dropped on "liver diet" alone.

\section{SUMMARY}

1. Studies of cardiac output and certain other functions of the circulation, have been conducted on eight subjects suffering from various types and degrees of anemia, the observations on each individual having been made both during the anemic state and after partial or complete recovery. 
2. In this series, there was a tendency for the following changes to occur during the anemic state:

a. Increased cardiac output.

$b$. Increased percentage utilization of oxygen by the tissues.

c. Decreased utilization of oxygen by the tissues in cubic centimeters per 100 cc. of blood.

$d$. In five instances, a relative increase in metabolic rate during severe anemia.

$e$. Low respiratory quotient; frequently this increased during recovery from anemia.

$f$. Increased $\Delta \mathrm{pH}$ (difference between arterial and venous serum $\mathrm{pH})$.

3. Of these changes, $(c),(e)$ and $(f)$ are shown to be consistent with the change in form of the $\mathrm{CO}_{2}$ dissociation curve in anemia. A balanced relationship between cardiac output $(a)$ and the percentage tissue utilization of oxygen (b) is possible, on the basis of vasomotor dilatation and lowered blood pressure in the anemic state. Blood pressure has been reported as lowered in anemia; vasomotor dilatation is to be expected when, as here, mean capillary or tissue oxygen tension is decreased.

4. A slightly modified Field-Bock method for measuring cardiac output, with portable apparatus, is described.

\section{PROTOCOLS}

F. L. Female, age 50. Diagnosis: Pernicious anemia.

History: Numbness and tingling of hands and feet for 18 months; weakness, dyspnea on exertion and edema of ankles for one year.

Physical examination: Pallor; deep reflexes hyperactive; legs spastic; slight edema of feet.

February 4: Red blood cells 1,400,000; hemoglobin 36 per cent.

February 22: Red blood cells 3,200,000; hemoglobin 68 per cent.

March 9: Red blood cells 4,300,000; hemoglobin 62 per cent (?).

Course: Striking improvement on liver diet.

J. K. Male, age 46. Diagnosis: Secondary anemia; purpura.

History: Dyspnea and weakness for one year; dizzy spells for one month.

Physical examination: Pallor; hemorrhagic areas on legs; eye ground hemorrhages.

February 13: Red blood cells 1,400,000; hemoglobin 29 per cent. 
February 18: Transfusion $800 \mathrm{cc}$.

March 8: Red blood cells 2,400,000; hemoglobin 45 per cent.

April 18: Red blood cells 2,800,000; hemoglobin 57 per cent.

Course: Gradual improvement with one transfusion and liver diet.

M. H. Female, age 40. Diagnosis: Ulcer of stomach; secondary anemia.

History: Sleepiness for two months; fever, nausea and vomiting for four weeks; fainted ten days before.

Physical examination: Pallor; stool guaiac ++++ . X-ray: penetrating ulcer of lesser curvature of stomach.

March 23: Red blood cells 3,000,000; hemoglobin 59 per cent.

March 29: Transfusion 500 cc.

May 16: Transfusion $400 \mathrm{cc}$.

May 19: Red blood cells 4,900,000; hemoglobin 86 per cent.

Course: Gradual improvement and disappearance of symptoms with transfusions; Sippy régime followed by liver diet later.

J. H. Male, age 50. Diagnosis: Ulcer of stomach; secondary anemia.

History: Operation for ulcer four years before; hematemesis and melena 18 months ago; weakness for last two or three months; tarry stools for one week.

Physical examination: Pallor; right rectus scar; small mass just under anterior abdominal wall; no free $\mathrm{HCl}$.

March 31: Red blood cells 2,200,000; hemoglobin 35 per cent.

April 2: Transfusion $600 \mathrm{cc}$.

April 27: Red blood cells 4,000,000; hemoglobin 60 per cent.

May 20: Red blood cells 3,900,000; hemoglobin 52 per cent.

Course: Gradual improvement on Sippy régime; one transfusion and iron injections.

W.S. Male, age 49. Diagnosis: Ulcer of duodenum; secondary anemia.

History: Attacks of gaseous eructations; flatulence and pain in epigastrium for twelve years. Loss of strength and weight and tarry stools for 6 weeks.

Physical examination: Pallor; palpable liver; stool and stomach contents guaiac ++++ .

April 8: Red blood cells 3,100,000; hemoglobin 55 per cent.

May 6: Red blood cells 3,900,000; hemoglobin 44 per cent.

Course: Bleeding stopped and strength returned on Sippy diet.

N. B. Male, age 50. Diagnosis: Ulcer of the duodenum; secondary anemia.

History: Epigastric pain and loss of weight nine months before; gastrojejunostomy six months before with relief; Vomited fresh blood six hours before admission.

Physical examination: Pallor; low blood pressure April 23.

May 17: Transfusion $500 \mathrm{cc}$.

May 23: Red blood cells 3,100,000; hemoglobin 34 per cent. 
June 3: Transfusion 500 cc.

June 8: Transfusion $550 \mathrm{cc}$.

June 10: Red blood cells 3,000,000; hemoglobin 40 per cent.

June 27: Red blood cells 3,800,000; hemoglobin 60 per cent.

Course: Continued bleeding until after third transfusion. Steady recovery thereafter on Sippy régime. No liver.

S.D. Female, age 36. Diagnosis: Pernicious anemia.

History: Pallor for three years; dyspnea; numbness and tingling of hands for two years; four transfusions without improvement; circulatory failure, generalized edema and dyspnea for four weeks.

Physical examination: Icteroid pallor; generalized edema.

June 3: Red blood cells 1,100,000; hemoglobin 20 per cent.

June 23: Red blood cells 1,170,000; hemoglobin 45 per cent.

July 12: Red blood cells 2,200,000; hemoglobin 45 per cent.

Course: Disappearance of edema, return of strength and color on Lilly's Liver. Extract.

J. J. Male, age 48. Diagnosis: Carcinoma with metastases following carcinoma of stomach; secondary anemia.

History: Loss of appetite for three months; pallor, weakness, dyspnea and loss of $30 \mathrm{lbs}$. for two months.

Physical examination: Icteroid pallor; systolic murmur; large liver; absent deep reflexes.

June 14: Red blood cells 680,000; hemoglobin 18 per cent.

June 16: Transfusion $450 \mathrm{cc}$.

July 6: Red blood cells 1,700,000; hemoglobin 34 per cent.

July 18: Red blood cells 2,400,000; hemoglobin 50 per cent.

Course: Temporary improvement on one transfusion and liver extract.

\section{BIBLIOGRAPHY}

1. Plesch, J., Ztschr. f. exper. Path. u. Therap., 1909, vi, 380. Hämodynamische Studien.

2. Morawitz, P., u. Röhmer, W., Deutsches Arch. f. klin. Med., 1908, xciv, 528. t'ber die Sauerstoffversorgung bei Anämien.

3. Liljestrand, G., and Stenström, N., Acta Med. Skandinav., 1926, lxiii, 130. The Influence of Variations in the Hemoglobin Content on the Blood Flow.

4. Dautrebande, L., Comt. Rend. de Soc. de Biol., 1925, xciii, 1029. Le Débit Cardiaque dans l'Anémie.

5. Field, H., Jr., Bock, A. V., Gildea, E. F., and Lathrop, F. L., J. Clin. Invest., 1925, $i, 65$. The Rate of the Circulation of the Blood in Normal Resting Individuals. 
6. Goldschmidt, S., and Light, A. B., J. Biol. Chem., 1925, lxiv, 53. A Method of Obtaining from Veins Blood Similar to Arterial Blood in Gaseous Content.

7. Peters, J. P., Bulger, H. A., and Eisenman, A. J., J. Biol. Chem., 1923, lviii, 747. Studies of the Carbon Dioxide Absorption Curve of Human Blood. 1V. The Relation of the Hemoglobin Content of Blood to the Form of the Carbon Dioxide Absorption Curve.

8. Peters, J. P., Bulger, H. A., and Eisenman, A. J., J. Biol. Chem., 1923, lv, 687. Studies of the Carbon Dioxide Absorption Curve of Human Blood. I. The Apparent Variations of $\mathrm{pK}_{1}$ in the Henderson-Hasselbalch Equation.

9. Bock, A. V., Field, H., Jr., and Adair, G. S., J. Biol. Chem., 1924, lix, 353 The Oxygen and Carbon Dioxide Dissociation Curves of Human Blood.

10. Blalock, A., and Harrison, T. R., Am. J. Physiol., 1927, 1xxx, 157. The Regulation of Circulation. V. The Effect of Anemia and Hemorrhage on the Cardiac Output of Dogs.

11. DuBois, E. F., Basal Metabolism in Health and Disease, Lea and Febiger, 1924.

12. Meyer, A. L., and DuBois, E. F., Arch. Int. Med., 1916, xvii, 965 . The Basal Metabolism in Pernicious Anemia.

13. Tompkins, E. H., Brittingham, E. H., and Drinker, C. K., Arch. Int. Med., 1919, xxiii, 441. The Basal Metabolism in Anemia, with Especial Reference to the Effect of Blood Transfusion on the Metabolism in Pernicious Anemia.

14. Barr, D. P., and Peters, J. P., J. Biol. Chem., 1921, xlv, 571. III. The Carbon Dioxide Absorption Curve and Carbon Dioxide Tension of the Blood in Severe Anemia.

15. Krogh, A., The Anatomy and Physiology of Capillaries. New Haven, 1922.

16. Tigerstedt, C., Skandinav. Arch. Physiol., 1909, xxii, 115. Zur Kenntnis der von dem Linken Herzen herausgetriebenen Blutmenge in ihrer Abhängigkeit von Verschiedenen Variabeln.

17. Henderson, Y., Am. J. Physiol., 1908, xxiii, 345. A Principle Underlying the Normal Variations in the Volume of the Blood Stream, and the Deviation from this Principle in Shock.

18. Keith, N. M., Rowntree, L. G., and Geraghty, J. T., Arch. Int. Med., 1915, xvi, 547. A Method for the Determination of Plasma and Blood Volume.

19. Austin, J. H., Cullen, G. E., Hastings, A. B., McLean, F. C., Peters, J. P., and Van Slyke, D. D., J. Biol. Chem., 1922, liv, 121. Technique for Collection and Analyses of Blood and for its Saturation with Gas Mixtures of Known Saturation. 